\title{
The Influence of Autumn Eurasian Snow Cover on the Atmospheric Dynamics Anomalies during the Next Winter in INMCM5 Model Data
}

\author{
Maria A. Tarasevich ${ }^{1,2}$, Evgeny M. Volodin ${ }^{2}$ \\ (C) The Authors 2021. This paper is published with open access at SuperFri.org
}

\begin{abstract}
The influence of autumn Eurasian snow cover on the atmospheric dynamics anomalies during the following winter is studied based on the INM RAS climate model data. The North Atlantic Oscillation is the leading pattern that causes the weather and climate variability in the Northern hemisphere. We evaluate the up-to-date model version (INMCM5) ability of the autumn Eurasian snow - winter NAO teleconnection simulation on different timescales. Maximum covariance analysis (MCA) is used to find winter atmospheric signals that are significantly correlated with autumn snow cover anomalies. Using MCA we conclude that Autumn Eurasian snow - winter NAO teleconnection is present in INMCM5 experiments on pre-industrial and present-day climate simulation. However, this method fails to show this phenomenon in experiments on a seasonal timescale. We conduct additional experiments on a seasonal timescale to assess the sensitivity of North Atlantic Oscillation index predictability to initial snow cover perturbations. These experiments demonstrate the absence of direct autumn Eurasian snow impact on the NAO index.

Keywords: climate model, seasonal hindcasts, North Atlantic Oscillation, Eurasian snow cover, teleconnection.
\end{abstract}

\section{Introduction}

A leading pattern affecting winter weather and climate variability over Northern hemisphere is the North Atlantic Oscillation (NAO) [17]. The NAO is defined as the fluctuation of the pressure gradient between the Stykkishólmur (Icelandic Low) and the Ponta Delgada (Azores High). The North Atlantic Oscillation represents the redistribution of atmospheric mass between the Arctic and the subtropical Atlantic. So the switch of the NAO phases is accompanied by large changes in surface air temperature, winds, storminess, and precipitation over the Atlantic as well as the adjacent continents. Thus the North Atlantic Oscillation typifies wintertime weather in Northern hemisphere extratropics. That is why the NAO phase prediction on seasonal to decadal timescales is an active goal for climate science centres [8, 24, 25, 36].

Several observations-based studies 4, 4, 5, 23, suggest the Eurasian snow cover in autumn as a source of predictability of the North Atlantic Oscillation in winter. The dynamical mechanism linking autumn Eurasian snow cover to the following wintertime climate is described in [4].

Modelling experiments forced with prescribed observations-based Eurasian snow cover anomalies also reproduce this teleconnection 10, 11, 13. However, even CMIP5, as well as CMIP3 Earth system models, cannot recover the autumn Eurasian snow - winter NAO relationship with internally-generated snow cover 12,14 .

In this paper we evaluate the INM RAS climate model's ability to simulate the autumn Eurasian snow cover - winter North Atlantic Oscillation teleconnection on different time scales. We also study the response of the model to initial snow cover perturbations.

The organization of this paper is as follows. Section 1 provides an overview of the INM RAS climate model and the numerical experiments' design. Section 2 describes the calculation of the North Atlantic Oscillation index and the simulated data processing methods. Section 3 discusses

\footnotetext{
${ }^{1}$ Moscow Institute of Physics and Technology, Dolgoprudny, Russian Federation

${ }^{2}$ Marchuk Institute of Numerical Mathematics of the Russian Academy of Sciences, Moscow, Russian Federation
} 
the results of simulating the teleconnection between Eurasian autumn snow and the following winter NAO phase. Finally, the conclusions summarize the results.

\section{Model and Data}

For all simulations we use the climate model developed in the INM RAS. The model is coupled, i. e., it consists of two global circulation ones: the atmosphere and the ocean models. The atmosphere model performs the solution of the hydrothermodynamic equations with hydrostatic approximation in advective form. The ocean model represents large scale hydrothermodynamic equations with hydrostatic and Boussinesq approximations.

In the study we use the up-to-date version of the INM RAS climate model called INMCM5 [30]. The spatial resolution of its global atmosphere circulation model is $2^{\circ} \times 1.5^{\circ}$ in longitude and latitude and 73 in vertical $\sigma$-levels. The stratosphere upper bound and its vertical resolution are $\sigma=0.0002$ (about $60 \mathrm{~km}$ ) and $500 \mathrm{~m}$ respectively. The interactive aerosol module 29] describing the concentration evolution of the 10 substances is included in the atmosphere model. The ocean global circulation model has horizontal resolution of $0.5^{\circ} \times 0.25^{\circ}$ in longitude and latitude and 40 vertical $\sigma$-levels. It includes dynamics and thermodynamics module 38 for the sea ice with the elastic-viscous-plastic rheology with a single gradation of thickness.

The atmosphere and the ocean global circulation models and the aerosol module are implemented as independent distributed applications that exchange data using MPI (Message Passing Interface) library when working in coupled mode.

The atmosphere global circulation model uses a semi-implicit discretization scheme that requires solving an auxiliary Helmholtz-type equation each dynamical step. In the current version a fast Fourier transform based algorithm is used which parallel implementation requires global data transposing. The scaling ability of this operation was studied in 22. Different approaches that employ the multigrid method on massively-parallel architecture are shown to scale better [21], but they require special hardware and are not used now.

The oceanic model step consists of several stages. The hardest stage of a step is the barotropic adaptation because it requires solving a system of three implicitly discretized equations for the velocity components and the ocean level. This system is solved iteratively using the PETSc package for distributed computations 27].

The INMCM5 is good in simulation of the present-day climate 30.31] as well as its changes in 1850-2014 28. This version of the INM RAS climate model takes part in the Coupled Model Intercomparison Project Phase 6 (CMIP6). In this study we use data of the following INMCM5 experiments: pre-industrial control (piControl), historical and seasonal hindcasts. The design of the piControl and the historical experiments was supplied by the CMIP6 9].

The piControl and the historical runs were performed on the supercomputer of the Joint Supercomputer Center of the Russian Academy of Sciences (720 cores of 8-core Intel Xeon E5-2690). The INMCM5 seasonal hindcasts were produced with the INM RAS supercomputer (160 cores of 12-core Intel Xeon Silver 4214).

\subsection{The piControl Run}

The pre-industrial control simulation is performed under all forcings fixed at conditions of the year of 1850. There are neither naturally occurring (e.g., volcanoes and Earth's orbital characteristics) nor human-induced (e.g., land usage and greenhouse gases emissions) changes in 
The Influence of Autumn Eurasian Snow Cover on the Atmospheric Dynamics...

forcings. As a part of the CMIP6, the piControl experiment is mostly used for the Earth system models evaluation and simulation of the intrinsic climate variability. The INMCM5 piControl run lasts for 1200 model years.

\subsection{Historical Runs}

The historical experiment is carried out under the evolving external forcings and the anthropogenic changes in atmospheric composition. Time series of the total solar irradiance and solar spectrum, greenhouse gases and stratospheric volcanic sulfate aerosol concentrations, as well as anthropogenic emissions of $\mathrm{SO}_{2}$, black and organic carbon, are prescribed based on observations.

The ensemble of ten INM RAS climate model historical runs was computed. The runs started with perturbed initial conditions obtained from the piControl one. The duration of each run is 165 model years from 1850 to 2014. The historical experiments demonstrate that INMCM5 simulates extreme climate and weather phenomena well [18, 26, 32.

\subsection{Seasonal Hindcasts}

Since recently we have been using the INMCM5 not only for climate modelling but also for weather hindcasting on a seasonal timescale. To obtain a hindcast for a winter season we set the initial states on November $1^{\text {st }}$. The initial states are constructed by eliminating the bias between the simulated climate and the observed one. The bias is eliminated by adding anomalies based on the reanalyses data to the INMCM5 1980-2014 climatology obtained from the ensemble of historical runs 34, 35. The reanalysis anomaly is the difference between the reanalysis data on November $1^{\text {st }}$ and its climatology. For the atmosphere and the land surface initial states we use ERA-Interim reanalysis [7]. The ocean initial states are obtained from SODA3.4.2 reanalysis [3].

The ensemble of the INMCM5 seasonal hindcasts was performed [34 35] for every winter in the 1981-2015 period. Each hindcast lasts for 5 model months (November-March). The ensemble consists of 10 members with slightly perturbed initial air temperature and wind speed. The hindcasts data is available upon request from the authors. The correlation analysis of various hindcasted weather fields and the study on the response to the quasi-biennial oscillation is presented in 35]. The North Atlantic Oscillation and the Pacific-North American indices as well as sudden stratospheric warming events predictability are discussed in 33,34 .

\subsection{ERA5 Reanalysis}

We compare the INMCM5 simulations with the state-of-the-art ERA5 reanalysis [15]. It is based on the Integrated Forecasting System (IFS) Cy41r2 with the incremental 4D-Var 11] data assimilation technique. The ERA5 covers the period from 1979 and continues to be extended forward in near real time. For our purposes we download the reanalysis data with the INMCM5 horizontal resolution for the 1981-2015 winter seasons directly from C3S Climate Data Store.

\section{Methods}

\subsection{Maximum Covariance Analysis (MCA)}

Following 37] we use MCA to study the possible Eurasian autumn snow influence on the winter Northern hemisphere atmospheric circulation anomalies. With maximum covariance anal- 
ysis two evolving fields $X_{i}(t), Y_{j}(t)$ are decomposed as:

$$
\begin{aligned}
X_{i}(t) & =\overline{X_{i}}+X_{i}^{(1)} a_{1}(t)+X_{i}^{(2)} a_{2}(t)+\ldots, \\
Y_{j}(t) & =\overline{Y_{j}}+Y_{j}^{(1)} b_{1}(t)+Y_{j}^{(2)} b_{2}(t)+\ldots
\end{aligned}
$$

Here each new term is obtained by maximization of the covariance between $a_{k}(t)$ and $b_{k}(t)$, $X_{i}^{(k)}, Y_{j}^{(k)}$ - two families of orthogonal modes with respect to the standard discrete $L_{2}$ inner product given by

$$
\left(Z_{p}^{(m)}, Z_{p}^{(n)}\right)_{L_{2}}=\sum_{p} w_{p} Z_{p}^{(m)} Z_{p}^{(n)}, \quad w_{p}=\cos \varphi_{p},
$$

where $\varphi_{p}$ stands for latitude of the $p$-th field point and $Z$ is either $X$ or $Y$. To work with more convenient Euclidean inner product, we scale the fields in the following manner

$$
\tilde{Z}_{p}=\sqrt{w_{p}} Z_{p}, \quad\left(Z_{p}^{(m)}, Z_{p}^{(n)}\right)_{L_{2}}=\left(\tilde{Z}_{p}^{(m)}, \tilde{Z}_{p}^{(n)}\right) \equiv \sum_{i} \tilde{Z}_{p}^{(m)} \tilde{Z}_{p}^{(n)}
$$

To perform MCA, we use singular value decomposition (SVD) 2]. First the covariance matrix $C$ is constructed:

$$
C=\left(c_{i j}\right), \quad c_{i j}=\frac{1}{N_{t}} \sum_{t=1}^{N_{t}}\left(\tilde{X}_{i}(t)-\tilde{X}_{i}\right)\left(\tilde{Y}_{j}(t)-\overline{\tilde{Y}_{j}}\right),
$$

then we compute the SVD of $C$ :

$$
c_{i j}=\sum_{k=1}^{r} \sigma_{k} \tilde{X}_{i}^{(k)} \tilde{Y}_{j}^{(k)}, \quad \sigma_{k}=\operatorname{cov}\left(a_{k}(t), b_{k}(t)\right) \equiv \frac{1}{N_{t}} \sum_{t=1}^{N_{t}} a_{k}(t) b_{k}(t) .
$$

The obtained $\tilde{X}_{i}^{(k)}, \tilde{Y}_{j}^{(k)}$ are orthonormal as they are left and right singular vectors. The modes $X_{i}^{(k)}, Y_{j}^{(k)}$ are rescaled further to satisfy condition $\operatorname{std} a_{k}(t)=\operatorname{std} b_{k}(t)=1$. Under this scaling $\sigma_{k}=\operatorname{corr}\left(a_{k}(t), b_{k}(t)\right)$.

In this research we apply the maximum covariance analysis in the region from $20^{\circ} \mathrm{N}$ to $80^{\circ} \mathrm{N}$ for the following fields:

- $\left\{X_{i}(t)\right\}$ - October-November Eurasian $\left(10^{\circ} \mathrm{W}-170^{\circ} \mathrm{W}\right)$ snow cover percentage (SC) and snow water equivalent (SWE) from the piControl and the historical runs; snow water equivalent on November $1^{\text {st }}\left(\mathrm{SWE}^{1 \mathrm{Nov}}\right)$ based on the ERA-Interim reanalysis from the seasonal hindcasts;

- $\left\{Y_{j}(t)\right\}$ - December-February (DJF) averaged monthly mean sea level pressure (SLP) produced by all of the considered INMCM5 experiments.

\subsection{North Atlantic Oscillation (NAO) Index Calculation}

The NAO index based on simulated or reanalyses data is usually calculated [16, 17] as the expansion coefficient of the leading Empirical Orthogonal Function (EOF) of the sea level pressure (SLP) anomalies over the Atlantic $\left(20^{\circ} \mathrm{N}-80^{\circ} \mathrm{N}, 90^{\circ} \mathrm{W}-40^{\circ} \mathrm{E}\right)$. The leading EOF is the first eigenvector of the SLP anomalies covariance matrix.

We compute the first empirical orthogonal function of winter (DJF) sea level pressure anomalies for the 1981-2015 period. The monthly mean SLP we obtain from the ERA5 reanalysis data. 


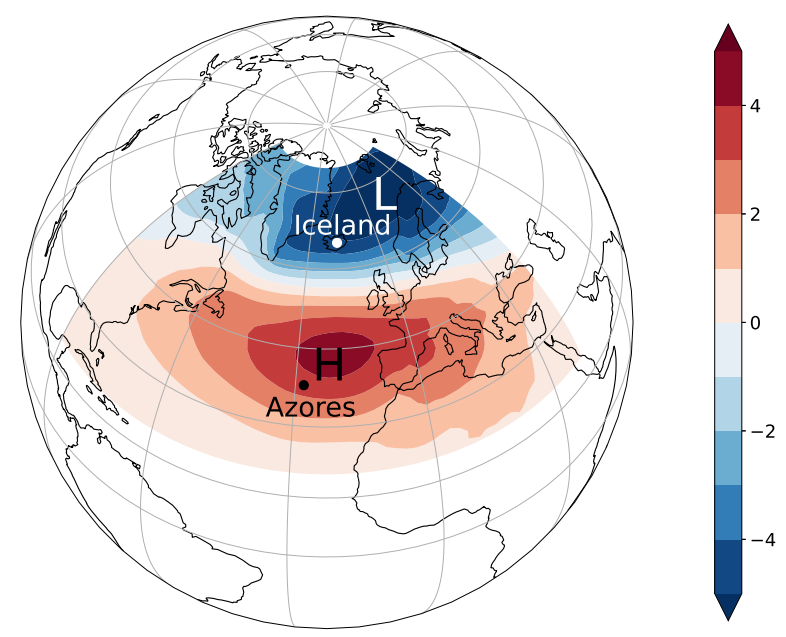

Figure 1. The first empirical orthogonal function of the DJF 1981-2015 sea level pressure anomalies based on ERA5 reanalysis data

The sea level pressure anomalies we compute relative to the reanalysis climatology over the considered period. Figure 1 shows the ERA5 leading EOF of the December-February averaged SLP anomalies.

We calculate the winter North Atlantic Oscillation index as the projection of the DJF sea level pressure anomalies on the ERA5 first empirical orthogonal function. We obtain December-February NAO index 1981-2015 time series $\mathrm{NAO}_{\mathrm{M}}$ and $\mathrm{NAO}_{\mathrm{R}}$ from the INMCM5 seasonal hindcasts ensemble mean and the ERA5 reanalysis SLP anomalies respectively. The $\mathrm{NAO}_{\mathrm{M}}$ and $\mathrm{NAO}_{\mathrm{R}}$ time series are normalized so that their standard deviations are equal to 1.

\subsection{Composites of the Anomalies}

\subsubsection{DJF sea level pressure}

We compute the DJF sea level pressure anomalies composite $C_{\text {SLP }}$ to find a pattern corresponding to the negative phase of the North Atlantic Oscillation. Using the December-February SLP over the $20^{\circ}-80^{\circ} \mathrm{N}$ domain and $\mathrm{NAO}_{\mathrm{R}}$ obtained from the ERA5 reanalysis data we calculate $C_{\mathrm{SLP}}$ :

$$
C_{\mathrm{SLP}}=\frac{\sum_{y: \mathrm{NAO}_{\mathrm{R}}(y)<0}(\mathrm{SLP}(y)-\overline{\mathrm{SLP}}) \cdot \mathrm{NAO}_{\mathrm{R}}(y)}{\sum_{y: \mathrm{NAO}_{\mathrm{R}}(y)<0} \mathrm{NAO}_{\mathrm{R}}(y)} .
$$

From here and thereafter the $y$ is the ordinal number of the year from the 1981-2015 period.

\subsubsection{Snow water equivalent on November $1^{\text {st }}$}

Snow water equivalent on November $1^{\text {st }} \mathrm{SWE}^{1 \text { Nov }}$ is used as initial state in seasonal hindcasts. It is computed from the ERA-Interim reanalysis and INMCM5 historical runs data:

$$
\operatorname{SWE}^{1 \mathrm{Nov}}(y)=\overline{\operatorname{SWE}_{\mathrm{M}}^{1 \mathrm{Nov}}}+\left(\operatorname{SWE}_{\mathrm{R}}^{1 \mathrm{Nov}}(y)-\overline{\mathrm{SWE}_{\mathrm{R}}^{1 \mathrm{Nov}}}\right) \cdot \frac{\operatorname{std}\left(\mathrm{SWE}_{\mathrm{M}}^{1 \mathrm{Nov}}\right)}{\operatorname{std}\left(\mathrm{SWE}_{\mathrm{R}}^{1 \mathrm{Nov}}\right)}
$$


With the $\mathrm{SWE}^{1 \mathrm{Nov}}$ anomalies in Eurasia over the $25^{\circ}-80^{\circ} \mathrm{N}$ latitudes and $\mathrm{NAO}_{\mathrm{M}}$ obtained from the INMCM5 seasonal hindcasts we calculate $C_{\mathrm{SWE}^{1 \mathrm{Nov}}}$ :

$$
C_{\mathrm{SWE}^{1 \mathrm{Nov}}}=\frac{1}{35} \sum_{y=1}^{35}\left(\mathrm{SWE}^{1 \mathrm{Nov}}(y)-\overline{\mathrm{SWE}_{\mathrm{M}}^{1 \mathrm{Nov}}}\right) \cdot\left(\mathrm{NAO}_{\mathrm{M}}(y)-\overline{\mathrm{NAO}_{\mathrm{M}}}\right) .
$$

Under the assumption of simple linear relation between $\mathrm{NAO}_{\mathrm{M}}(y)$ and $\operatorname{SWE}^{1 \mathrm{Nov}}(y)$ given by

$$
\mathrm{NAO}_{\mathrm{M}}(y)=\overline{\mathrm{NAO}_{\mathrm{M}}}+\int A \cdot\left(\operatorname{SWE}^{1 \mathrm{Nov}}(y)-\overline{\mathrm{SWE}_{\mathrm{M}}^{1 \mathrm{Nov}}}\right) d \Omega,
$$

the $C_{\mathrm{SWE}^{1 \mathrm{Nov}}}$ represents the perturbation of snow water equivalent that would result in increasing $\mathrm{NAO}_{\mathrm{M}}$ by 1 :

$$
\Delta \mathrm{NAO}_{\mathrm{M}}=\int A \cdot C_{\mathrm{SWE}^{1 \mathrm{Nov}}} d \Omega=\frac{1}{35} \sum_{y=1}^{35}\left(\mathrm{NAO}_{\mathrm{M}}(y)-\overline{\mathrm{NAO}_{\mathrm{M}}}\right)^{2}=\operatorname{var}\left(\mathrm{NAO}_{\mathrm{M}}(y)\right)=1
$$

\subsection{Data Processing and Significance Assessment}

The data of each INMCM5 experiment are grouped into a sequence of overlapping 35year intervals. For the piControl run we take every fifth year as interval start thus forming 234 intervals. For the historical runs we take each year as an interval start forming 130 intervals per ensemble member. Finally, for the seasonal hindcasts we have a single 35-year interval per ensemble member. In figures intervals are denoted by their first years.

For each of the 35-year intervals we perform MCA for the SLP and one of the snow describing field (SC, SWE and SWE ${ }^{1 \mathrm{Nov}}$ ). Only the leading pair of modes $X_{i}^{(1)}, Y_{j}^{(1)}$ is considered. We are also interested in the following quantities:

- temporal correlation coefficient for the leading pair

$$
\sigma_{1}=\operatorname{corr}\left(a_{1}(t), b_{1}(t)\right)
$$

- fraction of snow field variance, explained by its first mode term

$$
v_{1}^{X}=\frac{\operatorname{var}\left(X_{i}^{(1)} a_{1}(t)\right)}{\operatorname{var} X_{i}(t)}
$$

- same for the sea level pressure

$$
v_{1}^{Y}=\frac{\operatorname{var}\left(Y_{j}^{(1)} b_{1}(t)\right)}{\operatorname{var} Y_{j}(t)}
$$

- spatial correlation coefficient between the pressure mode and the SLP composite

$$
r=\operatorname{corr}_{L_{2}}\left(Y_{j}^{(1)}, C_{\mathrm{SLP}}\right)
$$

The $95 \%$ confidence intervals for each quantity are estimated using bootstrap technique [6].

For each experiment we plot $X_{i}^{(1)}$ and $Y_{j}^{(1)}$ averaged by all intervals for which $r$ is greater than the fifth percentile of all $r$ for that experiment, i. e., five percent of intervals with the least correlation between the pressure mode and the SLP composite are excluded from the average. 


\section{Results}

Following 11] we compute the sea level pressure anomaly composite that corresponds to the negative NAO phase from the ERA5 reanalysis data. This composite is shown in Fig. 2. It is later compared with pressure modes obtained by MCA.

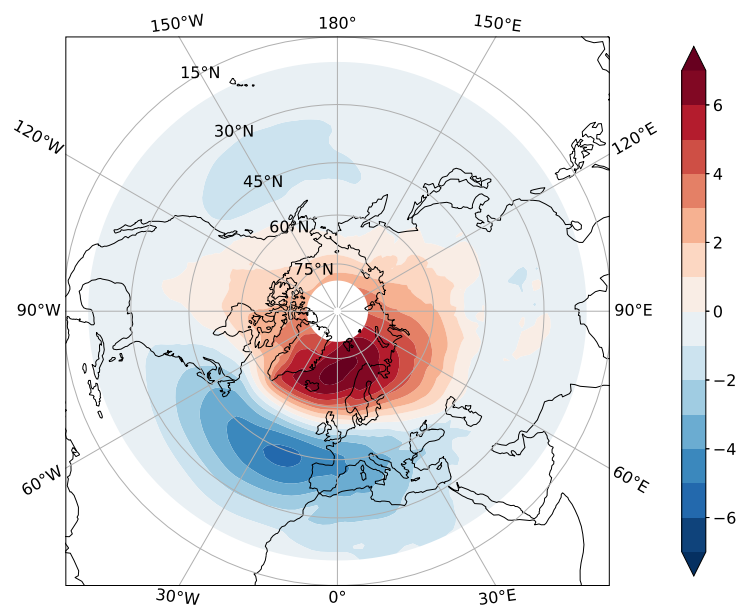

Figure 2. Composite of the sea level pressure anomalies corresponding to the negative NAO phase based on ERA5 reanalysis data $\left(C_{\mathrm{SLP}}, \mathrm{hPa}\right)$

\subsection{The piControl Run}

From the piControl data we study the autumn snow - winter pressure teleconnection using internally-generated snow cover percentage (SC) and snow water equivalent (SWE). We repeat MCA for 234 overlapping 35-year intervals that span the 1200-year run period.

The results of MCA applied to SC-SLP and SWE-SLP pairs are summarized in Tab. 1 and Tab. 2. Each table contains $\sigma_{1}$, the temporal correlation between the leading modes of snow and pressure; $v_{1}^{\mathrm{SC}}, v_{1}^{\mathrm{SWE}}$, the fraction of variance that is explained by the first mode of snow; $v_{1}^{\mathrm{SLP}}$, the fraction of variance that is explained by the first mode of pressure and $r$, the spatial correlation between the SLP mode and $C_{\mathrm{SLP}}$.

Table 1. Results of MCA applied to SC-SLP pair from the piControl run

\begin{tabular}{rcccc}
\hline & $\sigma_{1}, \%$ & $v_{1}^{\mathrm{SC}}, \%$ & $v_{1}^{\mathrm{SLP}}, \%$ & $r, \%$ \\
\hline mean & 74.1 & 7.1 & 28.2 & 65.9 \\
$95 \%$ confidence interval & {$[73.4,74.8]$} & {$[6.9,7.4]$} & {$[27.4,29.1]$} & {$[63.8,67.8]$} \\
\hline
\end{tabular}

Table 2. Results of MCA applied to SWE-SLP pair from the piControl run

\begin{tabular}{rcccc}
\hline & $\sigma_{1}, \%$ & $v_{1}^{\mathrm{SWE}}, \%$ & $v_{1}^{\mathrm{SLP}}, \%$ & $r, \%$ \\
\hline mean & 76.8 & 6.0 & 28.6 & 65.6 \\
$95 \%$ confidence interval & {$[76.3,77.4]$} & {$[5.8,6.1]$} & {$[27.8,29.4]$} & {$[63.6,67.2]$} \\
\hline
\end{tabular}

Figure 3 shows the spatial correlation coefficient $r$ plotted against the first year of the corresponding 35-year interval. For the most of intervals the correlation coefficient stays above $40 \%$. 


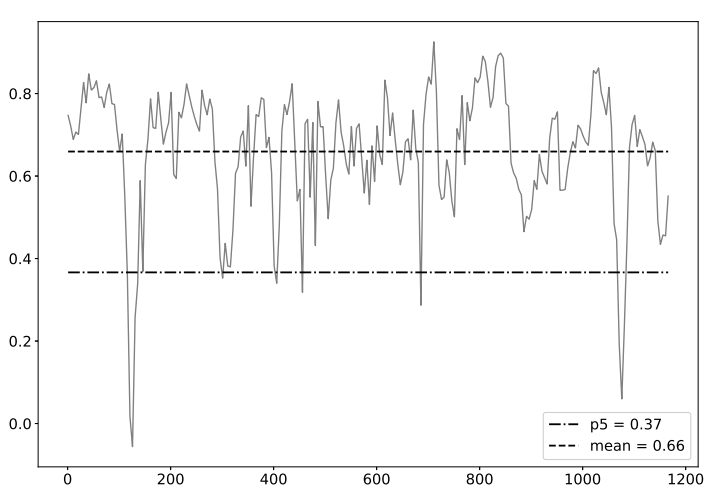

(a) SC-SLP pair

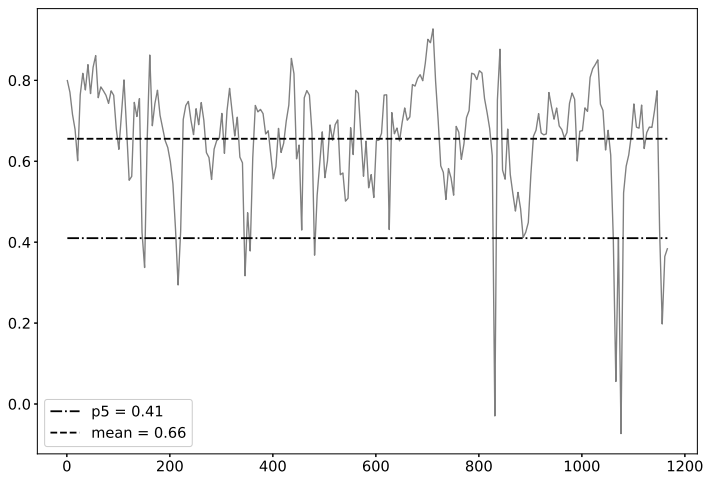

(b) SWE-SLP pair

Figure 3. Spatial correlation coefficient $r$ between the pressure mode and the SLP composite in piControl run for series of $234 \mathrm{MCA}$ experiments

Figures 4 and 5 show leading MCA modes for SC-SLP and SWE-SLP pairs averaged by all intervals except for those where spatial correlation $r$ was extremely low (below its fifth percentile).

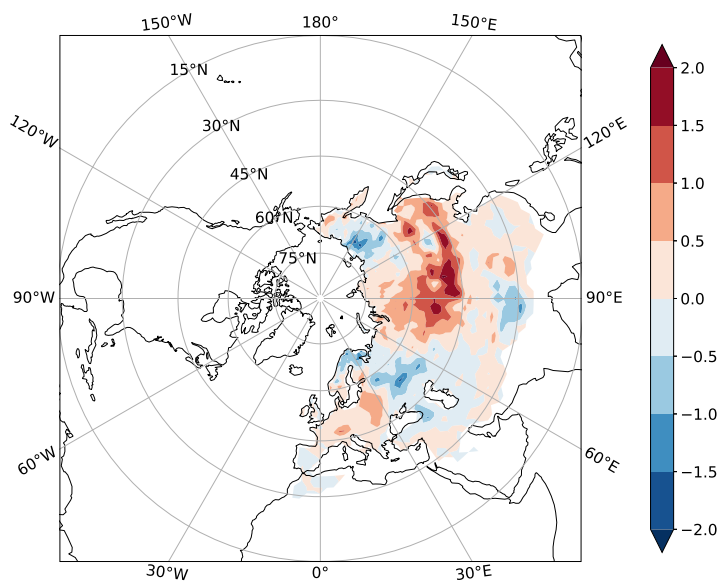

(a) SC leading mode, $\%$

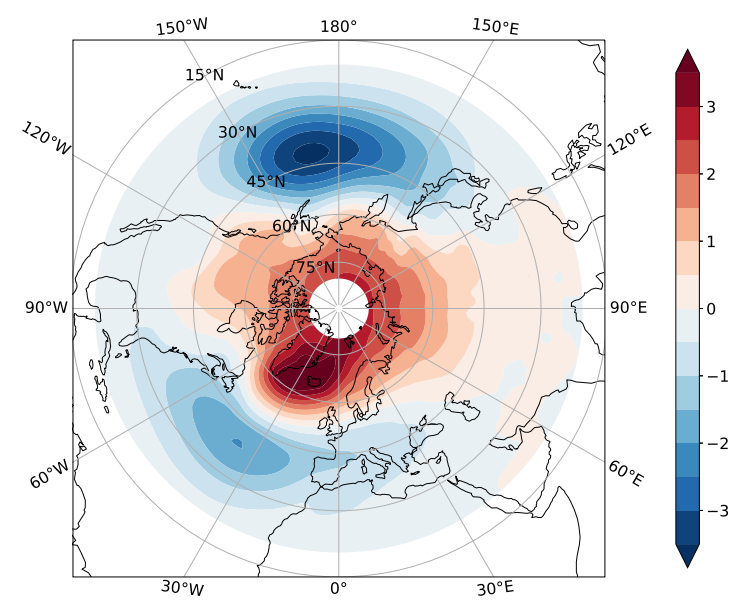

(b) SLP leading mode, hPa

Figure 4. Averaged leading MCA modes for SC-SLP pair in piControl run

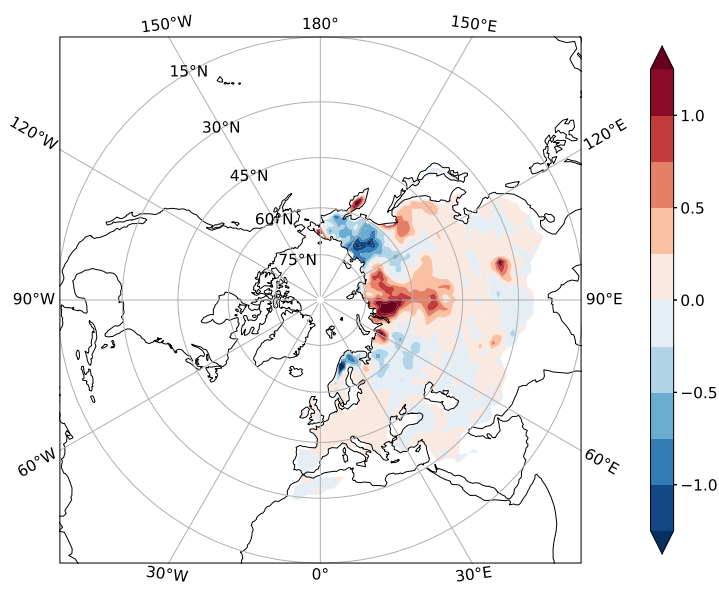

(a) SWE leading mode, mm

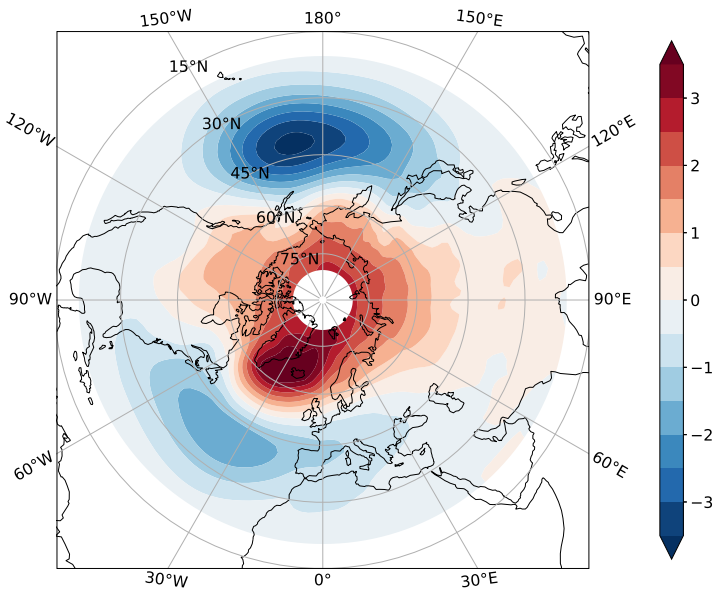

(b) SLP leading mode, $\mathrm{hPa}$

Figure 5. Averaged leading MCA modes for SWE-SLP pair in piControl run 
The SLP leading mode for the SC-SLP and SWE-SLP pairs is almost the same. It demonstrates typical North Atlantic Oscillation and Pacific-North American patterns.

The SC MCA first mode has its maximum in Siberia and its minimum in the East European Plain and is in good agreement with the results from [37].

The SWE mode demonstrates similar to SC distribution, but extrema are located closer to the North Pole.

\subsection{Historical Runs}

The key difference between piControl and historical runs is that the latter is carried out under evolving forcings. Like in the piControl run the data is grouped in 35-year intervals, except that now we take every model year as an interval start and have 10 ensemble members for each interval. Following results are obtained by treating each ensemble member separately, i. e., no ensemble averaging is performed to reduce the smoothing of the extrema.

Similar to piControl the MCA results for historical runs are summarized in Tab. 3 and Tab. 4

Table 3. Results of MCA applied to SC-SLP pair from the historical runs

\begin{tabular}{rcccc}
\hline & $\sigma_{1}, \%$ & $v_{1}^{\mathrm{SC}}, \%$ & $v_{1}^{\mathrm{SLP}}, \%$ & $r, \%$ \\
\hline mean & 72.9 & 6.9 & 29.0 & 63.8 \\
$95 \%$ confidence interval & {$[72.7,73.2]$} & {$[6.8,7.0]$} & {$[28.7,29.3]$} & {$[62.8,64.7]$} \\
\hline
\end{tabular}

Table 4. Results of MCA applied to SWE-SLP pair from the historical runs

\begin{tabular}{rcccc}
\hline & $\sigma_{1}, \%$ & $v_{1}^{\mathrm{SWE}}, \%$ & $v_{1}^{\mathrm{SLP}}, \%$ & $r, \%$ \\
\hline mean & 77.0 & 6.0 & 29.6 & 65.5 \\
$95 \%$ confidence interval & {$[76.7,77.2]$} & {$[5.9,6.1]$} & {$[29.3,30.0]$} & {$[64.5,66.4]$} \\
\hline
\end{tabular}

Figure 6 shows a scatter plot of the spatial correlation coefficient $r$ for each of the 10 ensemble members of the historical runs drawn against the first year of the corresponding interval.

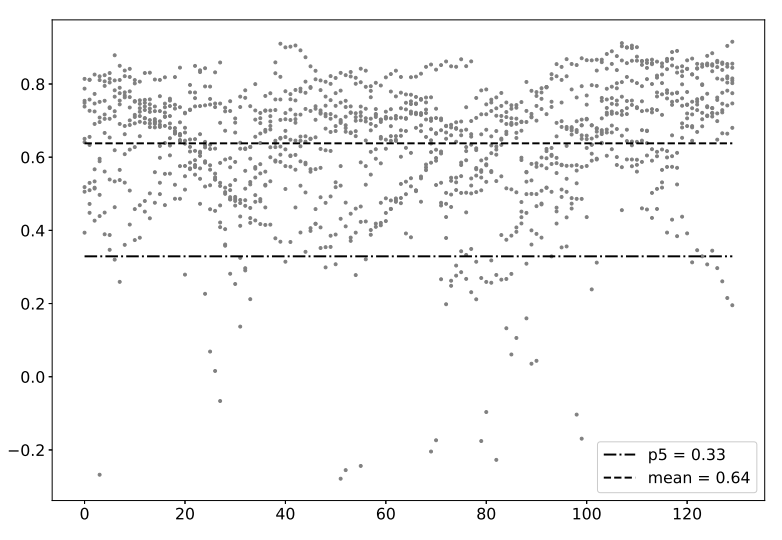

(a) SC-SLP pair

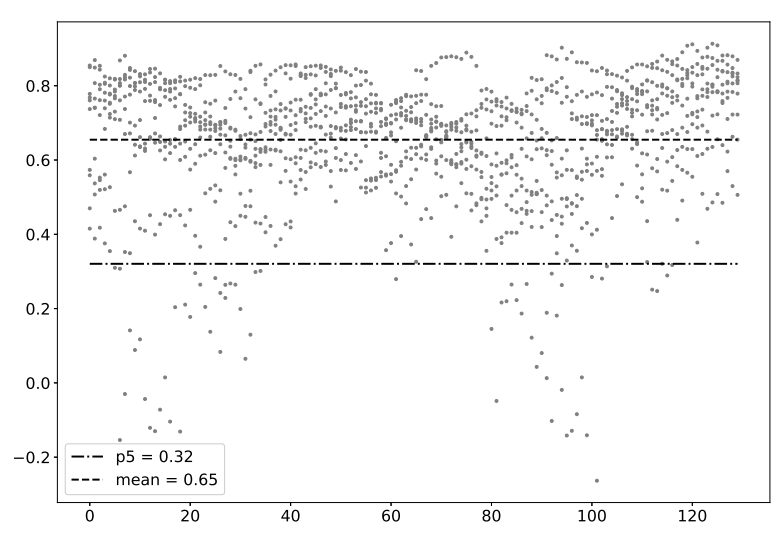

(b) SWE-SLP pair

Figure 6. Spatial correlation coefficient $r$ between the pressure mode and the SLP composite in 10 historical runs for series of $130 \mathrm{MCA}$ experiments 
Just like in the piControl case we drop $5 \%$ of outliers with the least value of the spatial correlation coefficient $r$ for each ensemble member and average the resulting set of pressure and snow modes. The averaged modes are presented in Fig. 7 and Fig. 8.

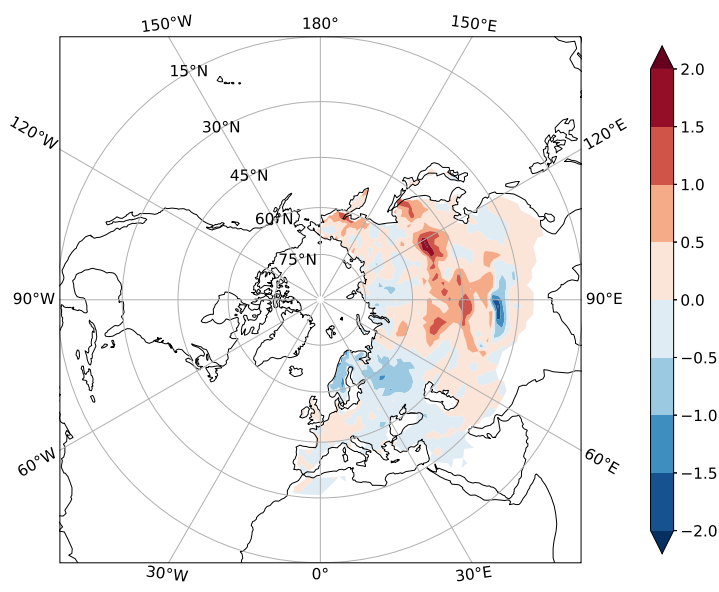

(a) SC leading mode, $\%$

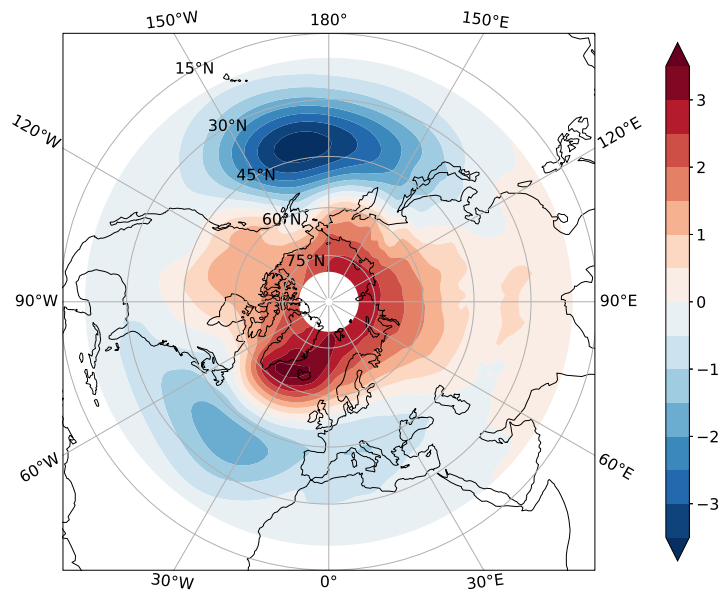

(b) SLP leading mode, $\mathrm{hPa}$

Figure 7. Averaged leading MCA modes for SC-SLP pair in historical runs

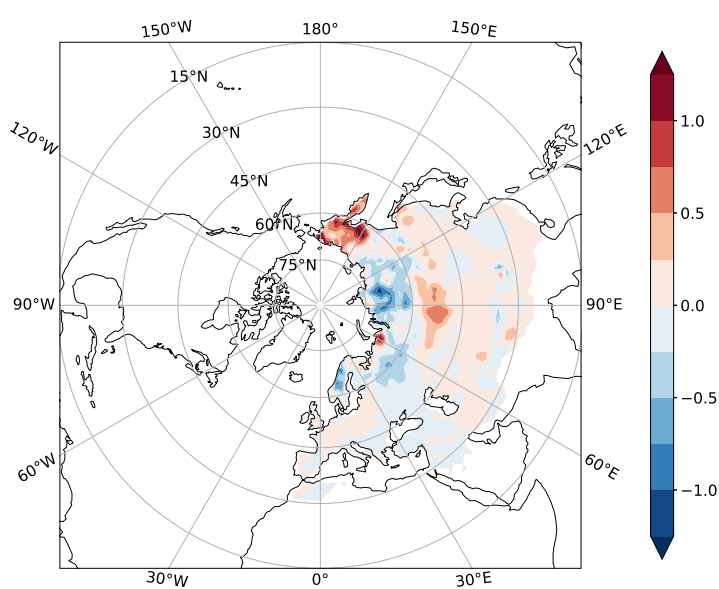

(a) SWE leading mode, $\mathrm{mm}$

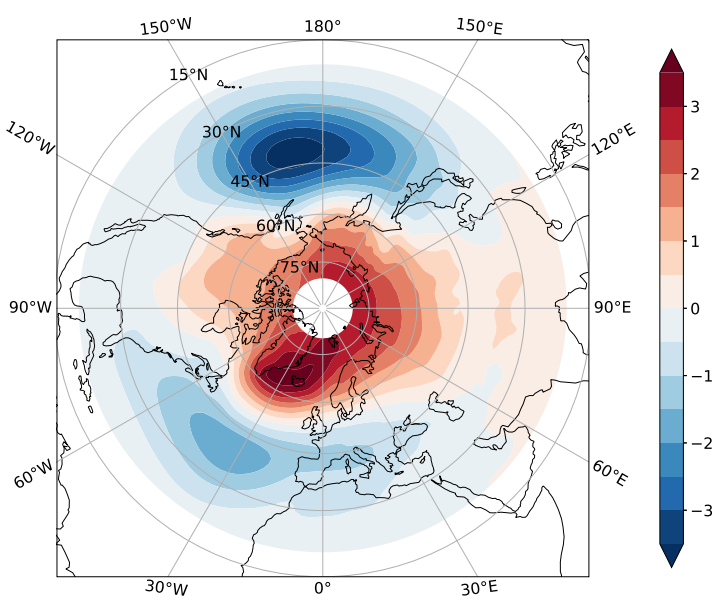

(b) SLP leading mode, $\mathrm{hPa}$

Figure 8. Averaged leading MCA modes for SWE-SLP pair in historical runs

The results obtained from historical runs are in excellent agreement with the ones from the piControl run, except for the snow modes that are slightly smoother. We believe this is due to averaging them over the individual ensemble members.

Comparing the results for piControl and historical runs we conclude that evolving forcings do not produce any significant impact on the simulation of the considered phenomenon.

\subsection{Seasonal Hindcasts}

From the results for piControl and historical runs it becomes clear that there is no significant difference whether we perform MCA on SC-SLP or SWE-SLP pair. In both cases we get quite close results for numerical quantities $\left(\sigma_{1}, v_{1}, r\right)$ as well as for averaged SLP mode. 
Thus for the seasonal hindcasts we do not consider SC and only focus on SWE ${ }^{1 \mathrm{Nov}}$. The other reason to do so is that $\mathrm{SC}$ is a diagnostic variable while $\mathrm{SWE}^{1 \mathrm{Nov}}$ is a prognostic variable. $\mathrm{SWE}^{1 \mathrm{Nov}}$ is explicitly set in the initial conditions for the November $1^{\text {st }}$ via 2 .

For the seasonal hindcasts we have only one 35-year interval and 10 ensemble members. The results of MCA performed for $\mathrm{SWE}^{1 \mathrm{Nov}}$ and SLP are summarized in Tab. 5 .

Table 5. Results of MCA applied to $\mathrm{SWE}^{1 \mathrm{Nov}}-\mathrm{SLP}$ pair from the seasonal hindcasts

\begin{tabular}{rcccc}
\hline & $\sigma_{1}, \%$ & $v_{1}^{\mathrm{SC}}, \%$ & $v_{1}^{\mathrm{SWE}^{1 \mathrm{Nov}}, \%}$ & $r, \%$ \\
\hline mean & 53.6 & 26.0 & 18.5 & 41.2 \\
$95 \%$ confidence interval & {$[50.3,57.5]$} & {$[23.6,27.5]$} & {$[15.3,21.2]$} & {$[26.1,55.2]$} \\
\hline
\end{tabular}

The SLP leading mode pattern presented in Fig. $9 \mathrm{~b}$ shows resemblance to the patterns obtained from piControl and historical runs, but the extrema in the Atlantic have less absolute value. In contrast, the $\mathrm{SWE}^{1 \mathrm{Nov}}$ pattern shown in Fig. 9a is noisy and lacks many features that it has in piControl and historical runs, for example in the Eastern Europe and the Southern Siberia regions.

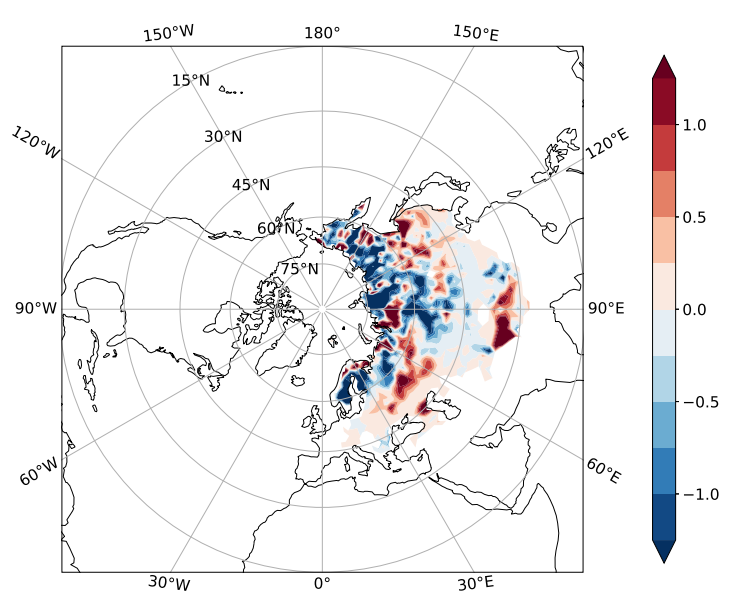

(a) $\mathrm{SWE}^{1 \mathrm{Nov}}$ leading mode, $\mathrm{mm}$

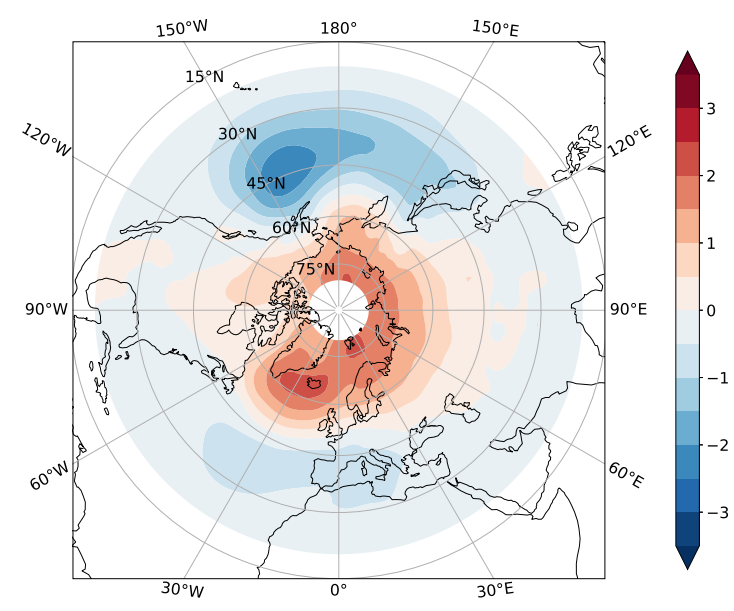

(b) SLP leading mode, hPa

Figure 9. Averaged leading MCA modes for $\mathrm{SWE}^{1 \mathrm{Nov}}-\mathrm{SLP}$ pair in seasonal hindcasts

The results from seasonal hindcasts significantly differ from the results in piControl and historical runs. There may be several explanations for this inconsistency:

- $\mathrm{SWE}^{1 \text { Nov }}$ field is not internally generated by the model but supplied from reanalysis instead;

- model run is not continuous because it is restarted each November $1^{\text {st }}$ with new initial conditions;

- snow itself might not be the only cause of the teleconnection.

\subsection{NAO Sensitivity to Perturbations of Initial Snow Water Equivalent}

To study the North Atlantic Oscillation sensitivity to snow water equivalent perturbations we carry out an ensemble of runs similar to seasonal hindcasts. The snow water equivalent anomaly is substituted with $\pm 2 \cdot C_{\mathrm{SWE}^{1 \text { Nov }}}$ and the other initial states are taken equal to INMCM5 climatology computed from the historical runs. The ensemble consists of 30 runs for each of the 
$\mathrm{SWE}^{1 \mathrm{Nov}}=\overline{\mathrm{SWE}_{\mathrm{M}}^{1 \mathrm{Nov}}}+2 \cdot C_{\mathrm{SWE}^{1 \mathrm{Nov}}}$ ("addition") and $\mathrm{SWE}^{1 \mathrm{Nov}}=\overline{\mathrm{SWE}_{\mathrm{M}}^{1 \mathrm{Nov}}}-2 \cdot C_{\mathrm{SWE}^{1 \mathrm{Nov}}}$ ("subtraction") experiments. The $C_{\mathrm{SWE}^{1 \text { Nov }}}$ is obtained by 3 and is presented in Fig. $10 \mathrm{a}$.

Assuming linear relation between NAO index and $\mathrm{SWE}^{1 \mathrm{Nov}}$ we expect the NAO index to be increased by 2 in the "addition" experiment and to be decreased by 2 in the "subtraction" experiment according to 4 .

The obtained values of NAO index for each ensemble member for both experiments are presented in Fig. 10b. The mean values of NAO index are $-0.07(95 \%$ CI $[-0.81,0.70])$ for the "subtraction" experiment and $0.23(95 \%$ CI $[-0.56,0.97])$ for the "addition" experiment. Mann-Whitney test [19], applied to the two series of NAO values produces pvalue $=0.46$ which means that there is no significant response in NAO index to altering $\mathrm{SWE}^{1 \mathrm{Nov}}$.

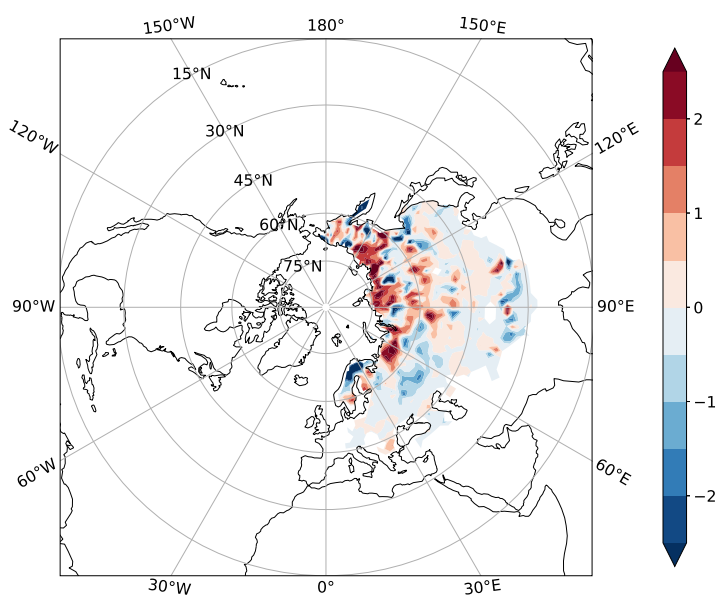

(a) Snow water equivalent composite $\left(C_{\mathrm{SWE}^{1 \mathrm{Nov}}}\right.$, $\mathrm{mm})$

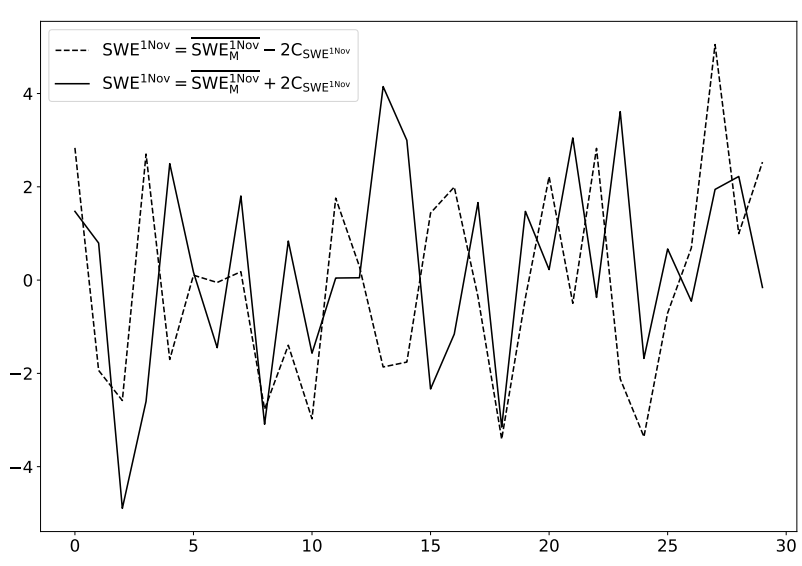

(b) NAO index plotted against the number of run

Figure 10. Sensitivity experiments to snow water equivalent perturbations

\section{Conclusion}

The piControl and historical runs show that INMCM5 is capable of simulating the autumn Eurasian snow - winter NAO teleconnection. This was not the case for the previous version of the model (INMCM4) which participated in CMIP5 [12, 20]. A possible explanation is that INMCM5 has a higher upper atmosphere bound than INMCM4 and has a finer vertical resolution in the stratosphere. According to [4], the stratosphere plays a key role in the mechanism of the teleconnection.

There is almost no difference in results obtained by applying MCA to SC-SLP and SWE-SLP pair which indicate that both snow coverage and snow water equivalent may be equally used to study the autumn snow influence on winter atmospheric circulation anomalies. The leading MCA mode of the sea level pressure has both North Atlantic Oscillation and Pacific-North American patterns.

A possible reason for INMCM5 seasonal hindcasts not capturing the phenomenon may be the way we feed the model with the reanalysis data. Instant change in prognostic variables can cause perturbations that might not settle on the seasonal time scale or might destroy the initial state pattern. These perturbations can be reduced by employing continuous observational or reanalysis data assimilation. 
The experiments of altering initial snow water equivalent in INMCM5 seasonal hindcasts indicate that Eurasian autumn snow itself does not significantly affect winter NAO. However, good teleconnection simulation obtained in piControl and historical runs might also indicate that autumn snow is only a manifestation of other phenomena that affect winter North Atlantic Oscillation in INMCM5.

\section{Acknowledgements}

The research was supported by the Russian Science Foundation, project No. 20-17-00190 (analysis of the piControl and historical runs) and by the Russian Foundation for Basic Research, project No. 20-05-00673 (analysis of the seasonal hindcasts and NAO sensitivity). The winter seasonal hindcasts and the sensitivity experiments were obtained using the HPC computation cluster at the Marchuk Institute of Numerical Mathematics of the Russian Academy of Sciences.

This paper is distributed under the terms of the Creative Commons Attribution-Non Commercial 3.0 License which permits non-commercial use, reproduction and distribution of the work without further permission provided the original work is properly cited.

\section{References}

1. Bonavita, M., Hólm, E., Isaksen, L., Fisher, M.: The evolution of the ECMWF hybrid data assimilation system. Quarterly Journal of the Royal Meteorological Society 142(694), 287-303 (2016). https://doi.org/10.1002/qj.2652

2. Bretherton, C.S., Smith, C., Wallace, J.M.: An Intercomparison of Methods for Finding Coupled Patterns in Climate Data. Journal of Climate 5(6), 541-560 (1992). https://doi. org/10.1175/1520-0442(1992)005<0541:AIOMFF>2.0.CO;2

3. Carton, J.A., Chepurin, G.A., Chen, L.: SODA3: A New Ocean Climate Reanalysis. Journal of Climate 31(17), 6967-6983 (2018). https://doi.org/10.1175/JCLI-D-18-0149.1

4. Cohen, J., Barlow, M., Kushner, P.J., Saito, K.: Stratosphere-Troposphere Coupling and Links with Eurasian Land Surface Variability. Journal of Climate 20(21), 5335-5343 (2007). https://doi.org/10.1175/2007JCLI1725.1

5. Cohen, J., Entekhabi, D.: Eurasian snow cover variability and northern hemisphere climate predictability. Geophysical Research Letters 26(3), 345-348 (1999). https://doi.org/10. 1029/1998GL900321

6. Davison, A.C., Hinkley, D.V.: Bootstrap Methods and their Application. Cambridge University Press, Cambridge (1997). https://doi.org/10.1017/CB09780511802843

7. Dee, D.P., Uppala, S.M., Simmons, A.J., et al.: The ERA-Interim reanalysis: configuration and performance of the data assimilation system. Quarterly Journal of the Royal Meteorological Society 137(656), 553-597 (2011). https://doi.org/10.1002/qj.828

8. Dunstone, N., Smith, D., Scaife, A.: Skilful predictions of the winter North Atlantic Oscillation one year ahead. Nature Geoscience 9(11), 809-814 (2016). https://doi.org/10. $1038 /$ ngeo2824 
9. Eyring, V., Bony, S., Meehl, G.A., et al.: Overview of the Coupled Model Intercomparison Project Phase 6 (CMIP6) experimental design and organization. Geoscientific Model Development 9(5), 1937-1958 (2016). https://doi.org/10.5194/gmd-9-1937-2016

10. Fletcher, C.G., Hardiman, S.C., Kushner, P.J., Cohen, J.: The Dynamical Response to Snow Cover Perturbations in a Large Ensemble of Atmospheric GCM Integrations. Journal of Climate 22(5), 1208-1222 (2009). https://doi.org/10.1175/2008JCLI2505.1

11. Fletcher, C.G., Kushner, P.J., Cohen, J.: Stratospheric control of the extratropical circulation response to surface forcing. Geophysical Research Letters 34(21), L21802 (2007). https://doi.org/10.1029/2007GL031626

12. Furtado, J.C., Cohen, J.L., Butler, A.H., et al.: Eurasian snow cover variability and links to winter climate in the CMIP5 models. Climate Dynamics 45(9), 2591-2605 (2015). https: //doi.org/10.1007/s00382-015-2494-4

13. Gong, G., Entekhabi, D., Cohen, J.: Modeled Northern Hemisphere Winter Climate Response to Realistic Siberian Snow Anomalies. Journal of Climate 16(23), 3917-3931 (2003). https://doi.org/10.1175/1520-0442(2003)016<3917:MNHWCR>2.0.CO;2

14. Hardiman, S.C., Kushner, P.J., Cohen, J.: Investigating the ability of general circulation models to capture the effects of Eurasian snow cover on winter climate. Journal of Geophysical Research: Atmospheres 113(D21), 123 (2008). https://doi.org/10.1029/ 2008JD010623

15. Hersbach, H., Bell, B., Berrisford, P., et al.: The ERA5 global reanalysis. Quarterly Journal of the Royal Meteorological Society 146(730), 1999-2049 (2020). https://doi.org/10. $1002 / q j .3803$

16. Hurrell, J.W.: Decadal Trends in the North Atlantic Oscillation: Regional Temperatures and Precipitation. Science 269(5224), 676-679 (1995). https://doi.org/10.1126/science. 269.5224 .676

17. Hurrell, J.W., Deser, C.: North Atlantic climate variability: The role of the North Atlantic Oscillation. Journal of Marine Systems 78(1), 28-41 (2009). https://doi.org/10.1016/j . jmarsys.2008.11.026

18. Kim, Y.H., Min, S.K., Zhang, X., et al.: Evaluation of the CMIP6 multi-model ensemble for climate extreme indices. Weather and Climate Extremes 29, 100269 (2020). https: //doi.org/10.1016/j.wace.2020.100269

19. Mann, H.B., Whitney, D.R.: On a Test of Whether one of Two Random Variables is Stochastically Larger than the Other. The Annals of Mathematical Statistics 18(1), 50-60 (1947). https://doi.org/10.1214/aoms/1177730491

20. Martynova, Y.V.: October snow cover and winter atmospheric conditions in Siberia. In: International Young Scientists School and Conference on Computational Information Technologies for Environmental Sciences, May 27 - June 6, 2019. IOP Conference Series: Earth and Environmental Science, vol. 386, p. 012001. IOP Publishing (2019). https://doi.org/10.1088/1755-1315/386/1/012001 
21. Mortikov, E.: The efficiency of the implementation of iterative methods for the solution of elliptic equations in atmospheric general circulation models on massively parallel systems. In: Sobolev, S., Voevodin, V. (eds.) 1st Russian Conference on Supercomputing Days 2015, RuSCDays 2015s. CEUR Workshop Proceedings, vol. 1482, pp. 528-534. CEUR-WS (2015), http://ceur-ws.org/Vol-1482/528.pdf

22. Mortikov, E.V.: Improving scalability of the high spatial resolution earth system model software complex. In: Parallelnye vychislitelnye tekhnologii (PaVT 2015). pp. 431-435 (2015), http://omega.sp.susu.ru/books/conference/PaVT2015/short/102.pdf, (in Russian)

23. Saito, K., Cohen, J., Entekhabi, D.: Evolution of Atmospheric Response to Early-Season Eurasian Snow Cover Anomalies. Monthly Weather Review 129(11), 2746-2760 (2001). https://doi.org/10.1175/1520-0493(2001)129<2746:EOARTE>2.0.C0;2

24. Scaife, A.A., Arribas, A., Blockley, E.: Skillful long-range prediction of European and North American winters. Geophysical Research Letters 41(7), 2514-2519 (2014). https://doi. org/10.1002/2014GL059637

25. Smith, D.M., Scaife, A.A., Eade, R.: Seasonal to decadal prediction of the winter North Atlantic Oscillation: emerging capability and future prospects. Quarterly Journal of the Royal Meteorological Society 142(695), 611-617 (2016). https://doi.org/10.1002/qj. 2479

26. Tarasevich, M.A., Volodin, E.M.: Influence of various parameters of INM RAS climate model on the results of extreme precipitation simulation. In: International Young Scientists School and Conference on Computational Information Technologies for Environmental Sciences, May 27 - June 6, 2019. IOP Conference Series: Earth and Environmental Science, vol. 386, p. 012012. IOP Publishing (2019). https://doi.org/10.1088/1755-1315/386/1/012012

27. Terekhov, K.M., Volodin, E.M., Gusev, A.V.: Methods and efficiency estimation of parallel implementation of the $\sigma$-model of general ocean circulation. Russ. J. Numer. Anal. Math. Modelling 26(2), 189-208 (2011).https://doi.org/10.1515/rjnamm.2011.011

28. Volodin, E.M., Gritsun, A.S.: Simulation of observed climate changes in 1850-2014 with climate model INM-CM5. Earth System Dynamics 9(4), 1235-1242 (2018). https://doi. org/10.5194/esd-9-1235-2018

29. Volodin, E.M., Kostrykin, S.V.: The aerosol module in the INM RAS climate model. Russian Meteorology and Hydrology 41(8), 519-528 (2016). https://doi.org/10.3103/ S106837391608001X

30. Volodin, E.M., Mortikov, E.V., Kostrykin, S.V., et al.: Simulation of modern climate with the new version of the INM RAS climate model. Izvestiya, Atmospheric and Oceanic Physics 53(2), 142-155 (2017). https://doi.org/10.1134/S0001433817020128

31. Volodin, E.M., Mortikov, E.V., Kostrykin, S.V., et al.: Simulation of the present-day climate with the climate model INMCM5. Climate Dynamics 49(11), 3715-3734 (2017). https: //doi.org/10.1007/s00382-017-3539-7 
32. Volodin, E.M., Tarasevich, M.A.: Simulation of Climate and Weather Extreme Indices with the INM-CM5 Climate Model. Russian Meteorology and Hydrology 43(11), 756-762 (2018). https://doi.org/10.3103/S1068373918110067

33. Vorobyeva, V., Volodin, E.: Analysis of the predictability of stratospheric variability and climate indices based on seasonal retrospective forecasts of the INM RAS climate model. Russian Journal of Numerical Analysis and Mathematical Modelling 36(2), 117-126 (2021). https://doi.org/10.1515/rnam-2021-0010

34. Vorobyeva, V., Volodin, E.: Evaluation of the INM RAS climate model skill in climate indices and stratospheric anomalies on seasonal timescale. Tellus A: Dynamic Meteorology and Oceanography 73(1), 1-12 (2021). https://doi.org/10.1080/16000870.2021.1892435

35. Vorobyeva, V.V., Volodin, E.M.: Experimental Studies of Seasonal Weather Predictability Based on the INM RAS Climate Model. Mathematical Models and Computer Simulations 13(4), 571-578 (2021). https://doi.org/10.1134/S2070048221040232

36. Wang, L., Ting, M., Kushner, P.J.: A robust empirical seasonal prediction of winter NAO and surface climate. Scientific Reports 7(1), 279 (2016). https://doi.org/10.1038/ s41598-017-00353-y

37. Wu, Q., Hu, H., Zhang, L.: Observed Influences of Autumn-Early Winter Eurasian Snow Cover Anomalies on the Hemispheric PNA-like Variability in Winter. Journal of Climate 24(7), 2017-2023 (2011). https://doi.org/10.1175/2011JCLI4236.1

38. Yakovlev, N.G.: Reproduction of the large-scale state of water and sea ice in the Arctic Ocean in 1948-2002: Part I. Numerical model. Izvestiya, Atmospheric and Oceanic Physics 45(3), 357-371 (2009). https://doi.org/10.1134/S0001433809030098 